Syntax Literate : Jurnal Ilmiah Indonesia p-ISSN: 2541-0849

e-ISSN : 2548-1398

Vol. 4, No. 12 Desember 2019

\title{
PENGARUH SELF-EFFICACY DAN SELF-ESTEEM TERHADAP PRESTASI BELAJAR MAHASISWA PADA SEKOLAH TINGGI ILMU KESEHATAN CIREBON
}

\author{
Abas Hidayat dan Fani Juliyanto Perdana \\ Sekolah Tinggi Ilmu Kesehatan (STIKes) Cirebon \\ Email: abasstikescirebon@gmail.com dan fanijuliyanto@gmail.com
}

\begin{abstract}
Abstrak
Penelitian ini bertujuan untuk mengetahui pengaruh self-efficacy dan self-esteem terhadap prestasi belajar mahasiswa baik secara parsial maupun simultan. Penelitian ini adalah penelitian kuantitatif besifat asosiatif yang bertujuan untuk mengetahui pengaruh ataupun juga hubungan antara dua variabel atau lebih. Jumlah sampel yang digunakan berdasarkan hasil perhitungan rumus Solvin dengan taraf signifikan 5\% yaitu sebanyak 278 responden yang diambil dengan teknik pengambilan simple random sampling. Data primer yang dikumpulkan langsung dari hasil pengisian angket skala Likert terhadap 278 responden. Data sekunder berupa daftar Indeks Prestasi Sementara (IPS) yang diperoleh dari bagian adminitrasi akademik Sekolah Tinggi Ilmu Kesehatan Cirebon. Hasil analisis uji hipotesis statistik secara parsial yaitu terdapat pengaruh yang signifikan secara parsial self-efficacy terhadap prestasi belajar mahasiswa, terdapat pengaruh yang signifikan secara parsial self-esteem terhadap prestasi belajar mahasiswa. Hasil uji hipotesis statistik secara simultan yaitu terdapat pengaruh yang signifikan secara simultan self-efficacy dan self-esteem terhadap prestasi belajar mahasiswa.
\end{abstract}

Kata kunci: Self-Efficacy, Self-Esteem, Prestasi Belajar

\section{Pendahuluan}

Pendidikan merupakan salah satu upaya agar seseorang mampu mengembangkan potensi diri melalui suatu proses pembelajaran. Di lingkungan perguruan tinggi yang dimaksud dengan keberhasilan dalam akademik yaitu di mana seorang mahasiswa mampu menunjukkan prestasi berupa nilai indeks prestasi yang tinggi. Keberhasilan prestasi belajar dapat dipengaruhi oleh beberapa faktor yaitu faktor eksternal dan internal (Muhibbin, 2010). Faktor eksternal seperti lingkungan, keluarga, sekolah dan masyarakat. Faktor internal seperti minat, bakat, disiplin, kecerdasan, dan motivasi dalam belajar.

Prestasi belajar dalam pengertian sederhana adalah capaian yang didapat oleh sang pembelajaran. Dalam mencapai capaian tersebut, seorang pembelajar harusnya 
melewati masa pengujian. Masa itu meliputi uji kompetensi dan pengujian sejenis. Pasca pengujian tersebut prestasi belajar akan nampak dari hasil yang diperoleh dari hasil pengujian (Gani, 2018).

Self-esteem merupakan salah satu bagian dari afektif yang perlu diperhatikan dalam dunia pendidikan. Self-esteem didefinisikan sebagai seberapa suka seseorang terhadap dirinya sendiri. Konsep self-esteem menggambarkan bahwasanya apabila seseorang menyukai, menerima dan hormat terhadap dirinya sendiri sebagai seorang yang berharga dan bermakna, maka semakin tinggi self-esteem (harga diri) seseorang tersebut. Self-esteem akan dapat menentukan semangat, antusiasme dan motivasi diri seseorang terutama dalam hal belajar. Self-esteem merupakan salah satu faktor afektif sebagai penentu keberhasilan dalam belajar. Oleh karena itu, mengetahui bagaimana tingkat self-esteem pelajar adalah hal penting dalam upaya meningkatkan prestasi belajar.

Penelitian tentang self-esteem ini masih perlu diteliti, terutama dikalangan mahasiswa yang kaitanya dengan prestasi belajar. Pada penelitian terdahulu menyatakan bahwa dari hasil uji hipotesis dinyatakan terdapat hubungan antara harga diri (selfesteem) dengan prestasi belajar pada mahasiswa tahun ke tiga Fakultas Kedokteran Universitas Riau (Rakasiwi, Zulharman, \& Firdaus, 2014). Beberapa ahli juga menyatakan terdapat korelasi antara self-esteem dengan prestasi akademik (Colquhoun \& Bourne, 2012). Selain itu beberapa ahli juga menyatakan bahwa bukanlah self-esteem yang mempengaruhi prestasi akademik, namun sebaliknya prestasi akademiklah yang akan mempengaruhi self-esteem. Beberapa pernyataan ahli terkait hubungan antara selfesteem dengan keberhasilan prestasi akademik, memberikan dorongan kepada peneliti untuk melakukan penelitian lebih lanjut tentang self-esteem dan keberhasilan prestasi akademik. Aspek self-esteem yang diukur yaitu kekuatan (power), keberartian (significance), kebijakan (viture) dan kompetensi (competence).

Selain self-esteem, self-efficacy juga salah satu bagian dari afektif yang perlu diperhatikan dalam upaya meningkatkan presatasi belajar. Self-efficacy itu sendiri yaitu merupakan penilaian diri, apakah seseorang mampu melakukan tindakan yang baik atau buruk, tepat atau salah, mampu atau tidak mampu mengerjakan sesuatu sesuai dengan yang dipersyaratkan. Self-efficacy menggambarkan tentang penilaian kemampuan diri (Martono, Rosa, \& Azmin, 2016). Self-efficacy merupakan sebagai bagian evaluasi 
seseorang mengenai kemampuan atau kompetensi dirinya untuk menyelesaikan suatu tugas, mencapai suatu tujuan dan mengatasi hambatan (Ghufron \& Rini Risnawita, 2010). Dalam rangka berupaya untuk meningkatkan prestasi belajar, maka salah satu nya diperlukan self-efficacy yang baik atau tinggi.

Penelitian tentang self-efficacy ini masih perlu diteliti, terutama di kalangan mahasiswa yang kaitanya dengan prestasi belajar. Pada penelitian terdahulu diperoleh bahwa self-efficacy berpengaruh secara signifikan terhadap prestasi belajar mahasiswa berprestasi. Berdasarkan saran yang diajukan di penelitian tersebut, bahwa perlu diadakan penelitian tentang self-efficacy tetapi kepada mahasiswa secara umum, bukan hanya yang berprestasi saja (Rizkiana, 2017).

Self-efficacy pada diri seseorang akan berbeda antara satu orang dengan yang lainnya berdasarkan tiga dimensi. Berikut adalah tiga dimensi tersebut (Ghufron \& Rini Risnawita, 2010). Dimensi tingkat (magnitude/Level) yaitu berkaitan dengan tingkat kesulitan yang diyakini oleh seseorang untuk dapat diselesaikan.

1. Strength yaitu berkaitan dengan tingkat kekuatan atau kelemahan keyakinan seseorang tentang kompetensi yang dipersepsinya.

2. Generality yaitu berkaitan dengan apakah keyakinan akan berlaku dalam berbagai macam aktifitas dan situasi.

\section{Metode Penelitian}

Jenis penelitian ini adalah penelitian kuantitatif bersifat asosiatif. Penelitian asosiatif merupakan penelitian yang bertujuan untuk mengetahui pengaruh ataupun juga hubungan antara dua variabel atau lebih (Haryati, 2012). Populasi penelitian adalah seluruh mahasiswa aktif di Sekolah Tinggi Ilmu Kesehatan Cirebon yang berjumlah 903 orang. Sampel penelitian ini dihitung menggunakan rumus Slovin dengan taraf signifikan 5\% yaitu sebanyak 278 responden yang diambil dengan teknik pengambilan simple random sampling. Penelitian ini dilakukan dari 1 maret 2019 sampai dengan 5 oktober 2019.

Pada penelitian ini data yang diambil berupa data primer dan data sekunder. Data primer yang dikumpulkan langsung dari hasil pengisian kuesioner/angket. Data skunder diperoleh dari bagian adminitrasi akademik Sekolah Tinggi Ilmu Kesehatan Cirebon. 
Definisi Operasional dan Pengukuran Variabel yaitu sebagai berikut:

a. Self-efficacy adalah variabel independen yaitu pengukuran self-efficacy terfokus pada tiga dimensi pada dimensi magnitude, dimensi strength, dan dimensi generality.

b. Self-Esteem adalah variabel independen yaitu pengukuran self-esteem terfokus pada kekuatan (power), keberartian (significance), kebijakan (viture), kompetensi (competence)

c. Prestasi belajar adalah variabel dependen yaitu pengukuran prestasi belajar terfokus pada nilai Indeks Prestasi Sementara.

Analisis data statistik yang dilakukan adalah analisis deskriptif yaitu gambaran presentase jumlah mahasiswa dan analisis inferensial yaitu uji homogenitas, uji normalitas, uji linearitas, uji multikolinearitas, uji heteroskedarisitas, uji Mann Whitney, Analisis Regresi dan Uji F.

\section{Hasil Penelitian}

\section{A. Deskripsi Self-efficacy}

\section{Deskripsi Self-efficacy pada Dimensi Tingkat (Magnitude/level)}

a. 22,66\% atau 63 mahasiswa memiliki kepercayaan diri yang sangat tinggi dalam mengerjakan tugas dari dosen. $75,54 \%$ atau 210 mahasiswa memiliki kepercayaan diri yang tinggi dalam mengerjakan tugas dari dosen. 1,80\% atau 5 mahasiswa ragu terhadap kepercayaan dirinya dalam mengerjakan tugas dari dosen.

b. $32,37 \%$ atau 90 mahasiswa memiliki kepercayaan diri sangat tinggi dalam mengerjakan ujian. 59,35\% atau 165 mahasiswa memiliki kepercayaan diri tinggi dalam mengerjakan ujian. 8,27\% atau 23 mahasiswa ragu terhadap kepercayaan dirinya dalam mengerjakan ujian.

c. $19,78 \%$ atau 55 mahasiswa memiliki kepercayaan diri sangat tinggi dalam memandang tugas sulit adalah sebagai tantangan. 58,27\% atau 162 mahasiswa memiliki kepercayaan diri tinggi dalam memandang tugas sulit adalah sebagai tantangan. 19,78\% atau 55 mahasiswa ragu terhadap kepercayaan dalam memandang tugas sulit adalah sebagai tantangan. 2,16\% 
atau 6 mahasiswa mempunyai kepercayaan diri rendah dalam memandang tugas sulit adalah sebagai tantangan.

d. 26,62\% atau 74 mahasiswa memiliki kepercayaan diri sangat tinggi terhadap potensi yang dimilikinya. 61,87\% atau 172 mahasiswa memiliki kepercayaan diri tinggi terhadap potensi yang dimilikinya. 11,51\% atau 32 mahasiswa ragu terhadap potensi yang dimilikinya.

e. 14,39\% atau 40 mahasiswa merencanakan dengan sangat matang dalam menyelesaikan tugas. 62,59\% atau 174 mahasiswa merencanakan dengan matang dalam menyelesaikan tugas. $21,22 \%$ atau 59 mahasiswa ragu terhadap perencanaan dalam menyelesaikan tugas. 1,80 atau 5 mahasiswa merencanakan dengan kurang matang dalam menyelesaikan tugas.

f. $18,71 \%$ atau 52 mahasiswa memiliki kepercayaan diri sangat tinggi terhadap kemampuan melaksanakan kuliah sesuai dengan kalender akademik. 79,14\% atau 220 mahasiswa memiliki kepercayaan diri tinggi terhadap kemampuan melaksanakan kuliah sesuai dengan kalender akademik. 2,16\% atau 6 mahasiswa yang ragu terhadap kemampuan melaksanakan kuliah sesuai dengan kalender akademik.

\section{Deskripsi Self-efficacy pada Dimensi Strength}

a. 44,60\% atau 124 mahasiswa mempunyai kepercayaan diri sangat tinggi terhadap keigigihan dan keuletan dalam menyelesaikan tugas. 53,96\% atau 150 mahasiswa mempunyai kepercayaan diri tinggi terhadap keigigihan dan keuletan dalam menyelesaikan tugas. $1,44 \%$ atau 4 mahasiswa ragu terhadap keigigihan dan keuletan yang dimilikinya dalam menyelesaikan tugas.

b. $31,65 \%$ atau 88 mahasiwa mempunyai kepercayaan diri yang sangat tinggi untuk berusaha keras dalam upaya meningkatkan prestasi akademik. 62,59\% atau 174 mahasiswa mempunyai kepercayaan diri yang tinggi untuk berusaha keras dalam upaya meningkatkan prestasi akademik. 5,76\% atau 16 mahasiswa ragu untuk berusaha keras dalam upaya meningkatkan prestasi akademik.

c. $28,42 \%$ atau 79 mahasiswa mempunyai kepercayaan diri yang sangat tinggi untuk berusaha dalam upaya mengembangkan kemampuan yang dimilikinya. 
61,15\% atau 170 mahasiswa mempunyai kepercayaan diri yang tinggi untuk berusaha dalam upaya mengembangkan kemampuan yang dimilikinya. $10,43 \%$ atau 29 mahasiswa ragu untuk berusaha dalam upaya mengembangkan kemampuan yang dimilikinya.

d. $30,58 \%$ atau 85 mahasiswa memiliki motivasi yang sangat tinggi untuk mengembangkan diri. $65,83 \%$ atau 183 mahasiswa memiliki motivasi yang tinggi untuk mengembangkan diri. 3,60\% atau 10 mahasiswa yang ragu untuk mengembangkan diri.

e. $24,10 \%$ atau 67 mahasiswa memiliki kepercayaan diri sangat tinggi untuk pantang menyerah apabila gagal. 59,35\% atau 165 mahasiswa memiliki kepercayaan diri tinggi untuk pantang menyerah apabila gagal. 16,55\% atau 46 mahasiswa ragu untuk pantang menyerah apabila gagal.

f. $28,42 \%$ atau 79 mahasiswa memiliki kepercayaan diri sangat tinggi untuk berpandangan positif dalam berbagai hal. 64,75\% atau 180 mahasiswa memiliki kepercayaan diri tinggi untuk berpandangan positif dalam berbagai hal. 6,83\% atau 19 mahasiswa ragu untuk berpandangan positif dalam berbagai hal.

\section{Deskripsi Self-efficacy pada Dimensi Generality}

a. 28,06\% atau 78 mahasiswa memperlihatkan keyakinan diri yang sangat tinggi pada seluruh proses perkuliahan. 65,47\% atau 182 mahasiswa memperlihatkan keyakinan diri yang tinggi pada seluruh proses perkuliahan. 6,47\% atau 18 mahasiswa memperlihatkan keraguan pada seluruh proses perkuliahan.

b. $27,34 \%$ atau 76 mahasiswa mempunyai keyakinan sangat tinggi terhadap kemampuan dalam menyelesaikan semua tugas dalam bentuk apapun dari semua dosen. 53,96\% atau 150 mahasiswa mempunyai keyakinan tinggi terhadap kemampuan dalam menyelesaikan semua tugas dalam bentuk apapun dari semua dosen. 17,99\% atau 50 mahasiswa ragu terhadap kemampuan menyelesaikan semua tugas dalam bentuk apapun dari semua dosen. 0,72 atau 2 mahasiswa mempunyai keyakinan rendah terhadap kemampuan dalam menyelesaikan semua tugas dalam bentuk apapun dari semua dosen. 
c. $31,29 \%$ atau 87 mahasiswa mempunyai kepercayaan diri sangat tinggi dalam mencoba tantangan baru. 60,43\% atau 168 mahasiswa mempunyai kepercayaan diri tinggi dalam mencoba tantangan baru. 8,27\% atau 23 mahasiswa ragu untuk mencoba tantangan baru.

d. 24,10\% atau 67 mahasiswa mempunyai kepercayaan diri sangat tinggi terhadap kemampuan mengembangkan potensi diri dalam berbagai bidang. 61,15\% atau 170 mahasiswa mempunyai kepercayaan diri tinggi terhadap kemampuan mengembangkan potensi diri dalam berbagai bidang. $14,75 \%$ atau 41 mahasiswa ragu terhadap kemampuan mengembangkan potensi diri dalam berbagai bidang.

e. $29,14 \%$ atau 81 mahasiswa mempunyai kepercayaan diri sangat tinggi terhadap kematangan dan kesiapan dalam menghadapi materi baru. 56,47\% atau 157 mahasiswa mempunyai kepercayaan diri tinggi terhadap kematangan dan kesiapan dalam menghadapi materi baru. 14,39\% atau 40 mahasiswa ragu terhadap kematangan dan kesiapan dirinya dalam menghadapi materi baru.

f. $28,78 \%$ atau 80 mahasiswa mempunyai kepercayaan diri sangat tinggi terhadap kesiapan diri untuk seluruh proses perkuliahan. 64,39\% atau 179 mahasiswa mempunyai kepercayaan diri tinggi terhadap kesiapan diri untuk seluruh proses perkuliahan. 6,83\% atau 19 mahasiswa ragu terhadap kesiapan diri untuk seluruh proses perkuliahan.

\section{B. Deskripsi Self-Esteem}

\section{Deskripsi Self-esteem pada Dimensi Kekuatan (Power)}

a. 23,38\% atau 65 mahasiswa mempunyai self-esteem yang sangat tinggi terhadap kemampuan mengontrol diri pada situasi yang sedang dihadapi dalam perkuliahan. 74,46\% atau 207 mahasiswa mempunyai self-esteem yang tinggi terhadap kemampuan mengontrol diri pada situasi yang sedang dihadapi dalam perkuliahan. 2,16\% atau 6 mahasiswa ragu terhadap kemampuan mengontrol diri pada situasi yang sedang dihadapi dalam perkuliahan.

b. 19,78\% atau 55 mahasiswa mempunyai self-esteem yang sangat tinggi terhadap kesadaran pada diri sendiri. 70,50\% atau 196 mahasiswa 
mempunyai self-esteem yang tinggi terhadap kesadaran pada diri sendiri. 9,71\% atau 27 mahasiswa ragu terhadap kesadaran pada diri sendiri.

\section{Deskripsi Self-esteem pada Dimensi Keberartian (Significance)}

a. 10,07\% atau 28 mahasiswa mempunyai self-esteem yang sangat tinggi terhadap keyakinan bahwa dirinya berarti bagi orang lain. 58,99\% atau 164 mahasiswa mempunyai self-esteem yang tinggi terhadap keyakinan bahwa dirinya berarti bagi orang lain. 30,94\% atau 86 mahasiswa ragu terhadap keyakinan bahwa dirinya berarti bagi orang lain.

b. $41,73 \%$ atau 116 mahasiswa mempunyai self-esteem yang sangat tinggi terhadap keyakinan bahwa dirinya dapat diterima orang lain. 53,96\% atau 150 mahasiswa mempunyai self-esteem yang tinggi terhadap keyakinan bahwa dirinya dapat diterima orang lain. 3,96\% atau 11 mahasiswa ragu terhadap keyakinan bahwa dirinya dapat diterima orang lain. 0,36 atau 1 mahasiswa mempunyai self-esteem yang rendah terhadap keyakinan bahwa dirinya dapat diterima orang lain.

\section{Deskripsi Self-esteem pada Dimensi Kebijakan (Viture)}

a. 25,90\% atau 72 mahasiswa mempunyai self-esteem yang sangat tinggi terhadap kemampuan bersikap positif dalam perkuliahan. 60,43\% atau 168 mahasiswa mempunyai self-esteem yang tinggi terhadap kemampuan bersikap positif dalam perkuliahan. $13,67 \%$ atau 38 mahasiswa ragu terhadap kemampuan bersikap positif dalam perkuliahan.

b. $23,38 \%$ atau 65 mahasiswa mempunyai self-esteem yang sangat tinggi terhadap kesungguhan dalam memecahkan masalah dalam perkuliahan. 73,38\% atau 204 mahasiswa mempunyai self-esteem yang tinggi terhadap kesungguhan dalam memecahkan masalah dalam perkuliahan. 3,24\% atau 9 mahasiswa ragu terhadap kesungguhannya dalam memecahkan masalah dalam perkuliahan.

\section{Deskripsi Self-esteem pada Dimensi Kompetensi (Competence)}

a. 27,70\% atau 77 mahasiswa mempunyai self-esteem yang sangat tinggi terhadap keyakinan bahwa dirinya berarti bagi orang lain. 69,42\% atau 193 mahasiswa mempunyai self-esteem yang tinggi terhadap keyakinan bahwa 
dirinya berarti bagi orang lain. 2,88\% atau 8 mahasiswa ragu terhadap keyakinan bahwa dirinya berarti bagi orang lain.

b. $26,62 \%$ atau 74 mahasiswa mempunyai self-esteem yang sangat tinggi terhadap keyakinan bahwa dirinya dapat diterima orang lain. 70,14\% atau 195 mahasiswa mempunyai self-esteem yang tinggi terhadap keyakinan bahwa dirinya dapat diterima orang lain. 3,24\% atau 9 mahasiswa ragu terhadap keyakinan bahwa dirinya dapat diterima orang lain.

\section{Deskripsi Prestasi Belajar}

Prestasi mahasiswa diukur dari indeks prestasi sementara dengan kategori sebagai berikut :

Tabel 1. Kategori Indeks Prestasi

\begin{tabular}{cc}
\hline Indeks Prestasi Sementara & Kategori \\
\hline $2,00-2,75$ & memuaskan \\
\hline $2,76-3,50$ & sangat memuaskan \\
\hline $3,51-4,00$ & dengan pujian (cumlaude $)$ \\
\hline
\end{tabular}

Berikut ini adalah data indeks prestasi sementara dari 278 responden. 3,96\% atau 11 mahasiswa mempunyai prestasi dengan kategori memuaskan. 88,13\% atau 245 mahasiswa mempunyai perstasi dengan kategori sangat memuaskan. 7,91\% atau 22 mahasiswa mempunyai prestasi dengan kategori dengan pujian (cumlaude).

D. Analisis Statistik

\section{Uji Homogenitas}

Tabel berikut hasil olah data SPSS terhadap uji homogenitas data selfefficacy dengan Indeks Prestasi Sementara (IPS).

Tabel 2. Test of Homogeneity of Variances

\begin{tabular}{cccc}
\hline Levene Statistic & df1 & df2 & Sig. \\
\hline 3,718 & 1 & 554 & 0,054 \\
\hline
\end{tabular}

Nilai Sig. 0,054 $\geq 0,05$ maka data self-efficacy dan Indeks Prestasi Sementara (IPS) bervariansi homogen, artinya self-efficacy dan Indeks Prestasi Sementara (IPS) berasal dari populasi yang tidak jauh berbeda keragamannya.

Tabel berikut hasil olah data SPSS terhadap uji homogenitas data selfesteem dengan Indeks Prestasi Sementara (IPS). 
Tabel 3. Test of Homogeneity of Variances

\begin{tabular}{cccc}
\hline Levene Statistic & df1 & df2 & Sig. \\
\hline 0,101 & 1 & 554 & 0,751 \\
\hline
\end{tabular}

Nilai Sig. 0,751 $\geq 0,05$ maka data self-esteem dan Indeks Prestasi Sementara (IPS) bervariansi homogen, artinya self-esteem dan Indeks Prestasi Sementara (IPS) berasal dari populasi yang tidak jauh berbeda keragamannya.

\section{Uji Normalitas}

Berikut ini adalah hasil olah data SPSS terhadap uji normalitas data selfefficacy, data self-esteem dan data Indeks Prestasi Sementara (IPS).

Tabel 4. Tests of Normality

\begin{tabular}{lrrrrrr}
\hline & \multicolumn{2}{c}{ Kolmogorov-Smirnov } & \multicolumn{3}{c}{ Shapiro-Wilk } \\
\cline { 2 - 7 } & Statistic & df & \multicolumn{1}{c}{ Sig. } & Statistic & df & \multicolumn{1}{c}{ Sig. } \\
\hline Self-efficacy & 0,069 & 278 & 0,003 & 0,980 & 278 & 0,001 \\
\hline Self-esteem & 0,067 & 278 & 0,004 & 0,983 & 278 & 0,002 \\
\hline IPS & 0,104 & 278 & 0,000 & 0,948 & 278 & 0,000 \\
\hline
\end{tabular}

a. Lilliefors Significance Correction

Berdasarkan tabel di atas, data self-efficacy, data self-esteem dan data IPS berdistribusi tidak normal. Hal ini dapat dilihat pada tabel di atas bahwa semua nilai sig. baik dengan menggunakan metode Kolmogorov Smirnov maupun metode Shapiro Wilk kurang dari 0,05.

\section{Uji Linearitas}

Berikut ini adalah hasil olah data uji linearitas terhadap data self-efficacy dan IPS menggunakan bantuan SPSS :

\section{Tabel 5. ANOVA}

\begin{tabular}{llrrrrc}
\hline Model & Sum of Squares & df & Mean Square & F & Sig. \\
\hline 1 & Regression & 1,806 & 1 & 1,806 & 33,120 & $0,000^{\mathrm{a}}$ \\
Residual & 15,054 & 276 & 0,055 & & \\
Total & 16,861 & 277 & & & \\
\hline
\end{tabular}

a. Predictors: (Constant), Self-efficacy

b. Dependent Variable: IPS

Berdasarkan Tabel 5 nilai Sig. $=0,00<0,05$ artinya data bersifat linear, sehingga data tersebut dapat digunakan untuk menjelaskan hubungan secara parsial self-efficacy terhadap prestasi belajar mahasiswa.

Berikut ini adalah hasil olah data uji linearitas terhadap data self-esteem dan IPS menggunakan bantuan SPSS : 
Tabel 6. ANOVA ${ }^{b}$

\begin{tabular}{llrrrrc}
\hline & Model & Sum of Squares & df & Mean Square & F & Sig. \\
\hline 1 & Regression & 1,466 & 1 & 1,466 & 26,274 & $0,000^{\mathrm{a}}$ \\
Residual & 15,395 & 276 & 0,056 & & \\
Total & 16,861 & 277 & & & \\
\hline
\end{tabular}

a. Predictors: (Constant), Self-esteem

b. Dependent Variable: IPS

Berdasarkan Tabel 5 nilai Sig. $=0,00<0,05$ artinya data bersifat linear, sehingga data tersebut dapat digunakan untuk menjelaskan hubungan secara parsial self-esteem terhadap prestasi belajar mahasiswa.

Berikut ini adalah hasil olah data uji linearitas terhadap data self-efficacy, self-esteem dan IPS menggunakan bantuan SPSS :

Tabel 7. ANOVA ${ }^{b}$

\begin{tabular}{llrrrrr}
\hline Model & \multicolumn{1}{c}{$\begin{array}{c}\text { Sum of } \\
\text { Squares }\end{array}$} & \multicolumn{1}{c}{ df } & $\begin{array}{c}\text { Mean } \\
\text { Square }\end{array}$ & F & Sig. \\
\hline 1 & Regression & 1,813 & 2 & 0,906 & 16,563 & $0,000^{\mathrm{a}}$ \\
& Residual & 15,048 & 275 & 0,055 & & \\
& Total & 16,861 & 277 & & & \\
\hline
\end{tabular}

a. Predictors: (Constant), self-esteem, self-efficacy

b. Dependent Variable: IPS

Berdasarkan Tabel 6 nilai Sig. $=0,00<0,05$ artinya data bersifat linear, sehingga data tersebut dapat digunakan untuk menjelaskan hubungan secara simultan self-efficacy dan self-esteem terhadap prestasi belajar mahasiswa.

\section{Uji Multikolinearitas}

Uji multikolinearitas dengan melihat nilai nilai Tolerance dan VIF dari data self-efficacy, self-esteem dan indeks prestasi sementara. Berikut ini adalah nilai Tolerance dan VIF dari data self-efficacy, self-esteem dan indeks prestasi sementara.

Tabel 8. Coefficients ${ }^{\mathrm{a}}$

\begin{tabular}{|c|c|c|c|c|c|c|c|}
\hline \multirow[b]{2}{*}{ Model } & \multicolumn{2}{|c|}{$\begin{array}{l}\text { Unstandardized } \\
\text { Coefficients }\end{array}$} & \multirow{2}{*}{$\begin{array}{c}\begin{array}{c}\text { Standardized } \\
\text { Coefficients }\end{array} \\
\text { Beta } \\
\end{array}$} & \multirow[b]{2}{*}{$\mathbf{t}$} & \multirow[b]{2}{*}{ Sig. } & \multicolumn{2}{|c|}{$\begin{array}{c}\text { Collinearity } \\
\text { Statistics }\end{array}$} \\
\hline & B & Std.Error & & & & Tolerance & VIF \\
\hline $1 \quad$ (Constant) & 1,866 & 0,270 & & 6,919 & 0,000 & & \\
\hline Self-efficacy & 0,281 & 0,112 & 0,293 & 2,519 & 0,012 & 0,239 & 4,176 \\
\hline Self-esteem & 0,044 & 0,132 & 0,039 & 0,336 & 0,737 & 0,239 & 4,176 \\
\hline
\end{tabular}

a. Dependent Variable: IPS 
Berdasarkan tabel di atas, nilai Tolerance self-efficacy dan self-esteem adalah lebih besar dari 0,10. Sementara itu, nilai VIF self-efficacy dan selfesteem lebih kecil dari 10,00. Sehingga dapat dinyatakan bahwa tidak multikolinearitas. Dengan kata lain, tidak terjadi korelasi antara data self-efficacy dan data self-esteem, sehingga dapat dilakukan model analisis regresi.

\section{Uji Heteroskedastisitas}

Berikut ini adalah scatterplot data self-efficacy, self-esteem dan IPS untuk menganalisis uji heteroskedastisitas.

\section{Gambar 1 Sctatter plot}

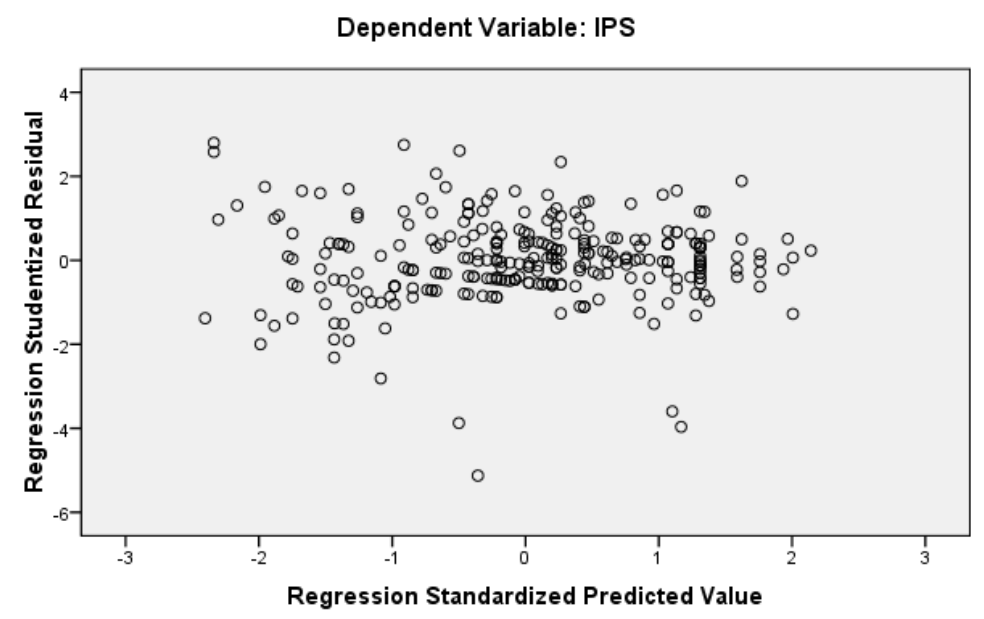

Berdasarkan scatterplot data self-efficacy, self-esteem dan IPS diketahui bahwa :

- Scatterplot tersebut menunjukkan titik-titik data penyebar berada di posisi atas, bawah dan disekitar angka 0

- Dari scatterplot tersebut terlihat bahwa titik-titik tidak berkumpul hanya di atas atau di bawah saja.

- Dari scatterplot tersebut terlihat bahwa penyebaran titik-titik data tidak membentuk pola bergelombang melebar kemudian menyempit dan melebar kembali.

- Dari scatterplot tersebut terlihat penyebaran titik-titik data tidak berpola.

Dengan demikian dapat simpulkan bahwa tidak terjadi adanya masalah heteroskedatisitas, sehingga model regresi yang baik dan ideal dapat terpenuhi dengan menggunakan data self-efficacy, self-esteem dan IPS. 


\section{Uji Mann Whitney (Parsial)}

Berdasarkan hasil uji homogenitas pada data self-efficacy dengan Indeks Prestasi Sementara (IPS) diperoleh data bervariansi homogen. Sedangkan hasil uji normalitas data self-efficacy dan Indeks Prestasi Sementara (IPS) berdistribusi tidak normal. dilakukan menggunakan uji non-parametrik, yaitu uji Mann Whitney.

Berikut ini adalah hasil olah data uji Mann Whitney menggunakan SPSS terhadap data self-efficacy dan indeks prestasi sementara dengan taraf signifikan 0,05 .

Tabel 9. Test Statistics ${ }^{\mathrm{a}}$

\begin{tabular}{lr}
\hline & Self-Efficacy dan IPS \\
\hline Mann-Whitney U & 188,000 \\
Wilcoxon W & 38969,000 \\
Z & $-20,313$ \\
Asymp. Sig. (2-tailed) & 0,000 \\
\hline
\end{tabular}

a. Grouping Variable: Pengelompokkan Self-Efficacy dan IPS

Berdasarkan tabel di atas nilai Sig.(2-tailed) $=0,000<\alpha=0,05$ artinya $\mathrm{H}_{0}$ ditolak. Sehingga dapat disimpulkan bahwa ada pengaruh yang signifikan secara parsial self-efficacy terhadap prestasi mahasiswa.

Berdasarkan hasil uji homogenitas pada data self-esteem dengan Indeks Prestasi Sementara (IPS) diperoleh data bervariansi homogen. Sedangkan hasil uji normalitas data self-esteem dan Indeks Prestasi Sementara (IPS) berdistribusi tidak normal.

Berikut ini adalah hasil olah data uji Mann Whitney menggunakan SPSS terhadap data self-efficacy dan indeks prestasi sementara dengan taraf signifikan 0,05 .

Tabel 10. Test Statistics ${ }^{\mathrm{a}}$

\begin{tabular}{lr}
\hline & Self-esteem dan IPS \\
\hline Mann-Whitney U & 55,500 \\
Wilcoxon W & 38836,500 \\
Z & $-20,385$ \\
Asymp. Sig. (2-tailed) & 0,000 \\
\hline a. Grouping Variable: Pengelompokkan Self-esteem dan IPS
\end{tabular}


Berdasarkan tabel di atas nilai Sig. $(2$-tailed $)=0,000<\alpha=0,05$ artinya $\mathrm{H}_{0}$ ditolak. Sehingga dapat disimpulkan bahwa ada pengaruh yang signifikan secara parsial self-esteem terhadap prestasi mahasiswa.

\section{Analisis Regresi}

Berdasarkan hasil uji asumsi statistik tehadap uji linearitas, uji multikolinearitas dan uji heteroskedastisitas diketahui bahwa data self-efficacy, data self-esteem dan data indeks prestasi sementara pada penelitian ini, adalah layak untuk dilakukan analisis regresi.

Berikut ini adalah hasil olah data SPSS pada regresi terhadap data selfefficacy dan data indeks prestasi sementara.

Tabel 11. Coefficients ${ }^{\mathrm{a}}$

\begin{tabular}{|c|c|c|c|c|c|}
\hline \multirow[b]{2}{*}{ Model } & \multicolumn{2}{|c|}{$\begin{array}{l}\text { Unstandardized } \\
\text { Coefficients }\end{array}$} & \multirow{2}{*}{$\begin{array}{c}\begin{array}{c}\text { Standardized } \\
\text { Coefficients }\end{array} \\
\text { Beta }\end{array}$} & \multirow[b]{2}{*}{$\mathrm{t}$} & \multirow[b]{2}{*}{ Sig. } \\
\hline & $\mathrm{B}$ & Std. Error & & & \\
\hline $1 \quad$ (Constant) & 1,914 & 0,228 & & 8,397 & 0,000 \\
\hline Self-efficacy & 0,314 & 0,055 & 0,327 & 5,755 & 0,000 \\
\hline
\end{tabular}

a. Dependent Variable: IPS

Hasil olah data self-efficacy dan IPS diketahui nilai konstantanya 1,914 dan nilai self-efficacy 0,314 . Sehingga diperoleh persamaan regresi $\mathrm{Y}=1,914+$ 0,314 X. Artinya jika nilai variabel self-effcacy nol, maka variabel IPSnya adalah 1,914. Koefisen regresi 0,314 menyatakan bahwa setiap terjadi peningkatan self-efficacy maka semakin meningkat pula prestasi belajar mahasiswa.

Berikut ini adalah hasil olah data SPSS pada regresi terhadap data selfesteem dan data indeks prestasi sementara.

Tabel 12. Coefficients ${ }^{\mathrm{a}}$

\begin{tabular}{|c|c|c|c|c|c|}
\hline \multirow[b]{2}{*}{ Model } & \multicolumn{2}{|c|}{$\begin{array}{l}\text { Unstandardized } \\
\text { Coefficients }\end{array}$} & \multirow{2}{*}{$\begin{array}{c}\text { Standardized } \\
\text { Coefficients } \\
\text { Beta }\end{array}$} & \multirow[b]{2}{*}{$\mathrm{t}$} & \multirow[b]{2}{*}{ Sig. } \\
\hline & $\mathrm{B}$ & Std. Error & & & \\
\hline $1 \quad$ (Constant) & 1,831 & 0,272 & & 6,736 & 0,000 \\
\hline Self-esteem & 0,335 & 0,065 & 0,295 & 5,126 & 0,000 \\
\hline
\end{tabular}

a. Dependent Variable: IPS

Hasil olah data self-efficacy dan IPS diketahui nilai konstantanya 1,831 dan nilai self-steem 0,335 . Sehingga diperoleh persamaan regresi $Y=1,831+$ 0,335 X. Artinya jika nilai variabel self-esteem nol, maka variabel IPSnya 
adalah 1,831. Koefisen regresi 0,335 menyatakan bahwa setiap terjadi peningkatan self-esteem maka semakin meningkat pula prestasi belajar mahasiswa.

\section{Uji F (Simultan)}

Berikut hasil olah data untuk uji $\mathrm{F}$ terhadap data self-efficacy, self-esteem dan IPS.

Tabel 13. ANOVA ${ }^{b}$

\begin{tabular}{|c|c|c|c|c|c|}
\hline Model & Sum of Squares & df & Mean Square & $\mathrm{F}$ & Sig. \\
\hline 1. & 1,813 & 2 & 0,906 & 16,563 & $0,000^{\mathrm{a}}$ \\
\hline Regression & 15,048 & 275 & 0,055 & & \\
\hline $\begin{array}{l}\text { Residual } \\
\text { Total }\end{array}$ & 16,861 & 277 & & & \\
\hline
\end{tabular}

a. Predictors: (Constant), Self-Esteem, Self-Efficacy

b. Dependent Variable: IPS

Berdasarkan Tabel tersebut bahwa diketahui nilai Sig. $=0,000$ lebih kecil dari 0,05 , maka artinya $\mathrm{H}_{0}$ ditolak, sehingga dapat diambil kesimpulan ada pengaruh yang signifikan secara simultan self-efficacy dan self-esteem terhadap prestasi mahasiswa

\section{Kesimpulan}

Terdapat pengaruh yang signifikan secara parsial self-efficacy terhadap prestasi belajar mahasiswa. Terdapat pengaruh yang signifikan secara parsial self-esteem terhadap prestasi belajar mahasiswa. Terdapat pengaruh yang signifikan secara simultan self-efficacy dan self-esteem terhadap prestasi belajar mahasiswa. 


\section{BIBLIOGRAFI}

Colquhoun, L. K., \& Bourne, P. A. (2012). Self-Esteem and Academic Performance of $4^{\wedge}$ (th) Graders in two Elementary Schools in Kingston and St. Andrew, Jamaica. Asian Journal of Business Management, 4(1), 36-57.

Gani, M. A. (2018). Pengaruh Disiplin Diri Dan Motivasi Belajar Terhadap Prestasi Belajar Mahasiswa Akademi Maritim Cirebon. Syntax Literate; Jurnal Ilmiah Indonesia, 3(2), 82-93.

Ghufron, M. N., \& Rini Risnawita, S. (2010). Teori-Teori Psikologi, yogyakarta. ArRuzz Media.

Haryati, S. (2012). Research and Development (R\&D) sebagai salah satu model penelitian dalam bidang pendidikan. Majalah Ilmiah Dinamika, 37(1), 15.

Martono, N., Rosa, H. T., \& Azmin, G. G. (2016). Mekanisme pertahanan ego pada tokoh transgender dalam novel Pasung Jiwa karya Okky Madasari: Suatu kajian psikologi sastra. Arkhais-Jurnal Ilmu Bahasa Dan Sastra Indonesia, 7(2), 87-92.

Muhibbin, S. (2010). Psikologi pendidikan dengan pendekatan baru. Bandung: PT Remaja Rosdakarya.

Rakasiwi, P. F., Zulharman, Z., \& Firdaus, F. (2014). Hubungan Harga Diri dengan Prestasi Belajar Mahasiswa Tahun Ketiga Fakultas Kedokteran Universitas Riau. None, 2(1), 1-7.

Rizkiana, A. (2017). Pengaruh self efficacy terhadap hasil belajar mahasiswa berprestasi (mawapres) STKIP PGRI Bangkalan. EQUILIBRIUM: Jurnal Ilmiah Ekonomi Dan Pembelajarannya, 5(2), 117-122. 